\title{
Unusual case of myocardial injury induced by Escherichia coli sepsis
}

\author{
Un caso inusuale di danno miocardico \\ indotto da sepsi da Escherichia Coli
}

\author{
Gaetano Gentile, Ester Meles, Claudio Carbone, Edoardo Cantù, Stefano Maggiolini
}

\begin{abstract}
Unusual case of myocardial injury induced by Escherichia coli sepsis. G. Gentile, E. Meles, C. Carbone, E. Cantù, S. Maggiolini.

The typical symptoms and signs of myocardial infarction are well known. Alterations in electrocardiogram (ECG), echocardiography or biochemical markers of myocardial necrosis are usually helpful to confirm the diagnosis. Some of these features, however, also occur in myocarditis, which is a potential differential diagnosis. We describe an unusual case
\end{abstract}

\begin{abstract}
of bacterial sepsis due to Escherichia coli that caused myocardial damage (myocarditis) with ECG changes mimicking acute myocardial infarction. The possible pathophysiological mechanisms of myocardial injury in sepsis are also reviewed.

Keywords: myocarditis, myocardial injury, myocardial dysfunction, endotoxin, lipopolysaccharide, sepsis, septic heart, cardiac troponins.
\end{abstract}

Monaldi Arch Chest Dis 2010; 74: 40-43.

Cardiology Unit, San Leopoldo Mandic Hospital, Merate (LC), Italy.

Corresponding author: Gaetano Gentile, MD; Cardiology Unit, San Leopoldo Mandic Hospital; I-22055 Merate (LC), Italy; Tel: +390395916293; fax +390395916471; E-mail address: gaetanogentile@alice.it

\section{Case report}

The patient was a 65 -year-old man without a history of cardiovascular disease. He underwent left pneumonectomy for lung cancer 19 years earlier and prostatectomy for prostate cancer 10 days before hospital admission. He experienced no postoperative complications. Eight days after surgery, after a scheduled urological examination with rectal exploration, the patient developed fever up to $39^{\circ} \mathrm{C}$ and pollakiuria. Owing to his health conditions, he went to the city hospital emergency room. No chest pain or other symptoms of acute coronary syndrome were observed at the time of first medical examination. Routine ECG, however, showed significant alterations with ST-segment elevation in V1-V3 and STsegment depression with deep negative $T$ waves in V4-V6, D1-D3, and aVF (Fig. 1). This prompted us to include cardiac troponin I (cTnI) determination in the routine blood chemistry assessment, which was found slightly increased $(0.1 \mathrm{ng} / \mathrm{ml} ;$ n.v. $<0.06$ $\mathrm{ng} / \mathrm{ml})$. Other exams showed normal values of hemoglobin $(14.8 \mathrm{~g} / \mathrm{dl})$, white blood cell count (WBC, $\left.4.1^{*} 10^{\wedge} 9 / 1\right)$; platelets (216 10^9/1); creatine kinase (52 U/l; n.v. 25-195 U/l), sodium (142 mmol/l; n.v. $134-146 \mathrm{mmol} / \mathrm{l})$, potassium $(4.0 \mathrm{mmol} / \mathrm{l}$; n.v. 3.6$5.0 \mathrm{mmol} / \mathrm{l})$, and slightly increased creatinine $(1.52$ $\mathrm{mg} / \mathrm{dl} ;$ n.v. $<1.2 \mathrm{mg} / \mathrm{dl}$ ) and transaminase levels (72 U/l; n.v. <40 U/l). Echocardiography was performed immediately, showing left ventricular hypertrophy, normal ejection fraction (58\%), wall motion abnormalities with hypokinesia of the medium-apical seg- ments of the inferior and infero-lateral wall, and no pericardial effusion.

Owing to the complete absence of symptoms and of any correlation between the ECG changes mimicking an antero-septal ST-elevation myocardial infarction (STEMI) and the echocardiography findings, the diagnosis of STEMI was excluded and the patient did not receive immediate reperfusion therapy (thrombolysis or percutaneous coronary intervention). He was transferred to the intensive cardiac care unit (ICCU) of our hospital for observation and to rule out transient asymptomatic cardiac ischemia. On ICCU admission, a new ECG was recorded one hour apart from the previous one, which showed resolution of ST-segment elevation with persistent negative T waves in V4-V6, D1, and aVL (Fig. 2).

Standard therapy for acute coronary syndrome with enoxaparin $(1 \mathrm{mg} / \mathrm{kg}$ twice daily), clopidogrel (loading dose of $300 \mathrm{mg}$ followed by $75 \mathrm{mg} / \mathrm{die}$ ), acetylsalicylic acid (100 mg/die), metoprolol $(25 \mathrm{mg}$ tid), and i.v. isosorbide dinitrate (stopped after 3 hours due to hypotension) were administered. Because of the relatively high temperature of $37.5^{\circ} \mathrm{C}$ at the time of hospitalization, acetaminophen $(500 \mathrm{mg}$ twice daily) and broad-spectrum antibiotic therapy with amoxicillin/clavulanic acid were also started after blood sample collection for hemoculture.

Six hours later, cTnI measurement showed rising cTnI levels up to $10.22 \mathrm{ng} / \mathrm{ml}$. After 10 hours, the ECG returned to normal (Fig. 3), cTnI began to decline $(9.18 \mathrm{ng} / \mathrm{ml}), \mathrm{WBC}$ rose to $17.6^{*} 10^{\wedge} 9 / 1$, and the temperature was unchanged $\left(37.6^{\circ} \mathrm{C}\right)$. 
The following day, blood culture showed growth of Escherichia coli (E. coli). Urine examination revealed significant leukocyturia $(1727 / \mu 1 ;$ n.v. $<20 / \mu \mathrm{l})$, bacteriuria and elevated C-reactive protein $(37.5 \mathrm{mg} / \mathrm{dl}$; n.v. $<1 \mathrm{mgl} / \mathrm{dl})$. All these findings combined with the patient history were consistent with sepsis from urinary tract infection. Antibiotic therapy was modified accordingly, starting cefepime $1 \mathrm{~g}$ twice daily based on antibiogram sensitivity of the isolated bacterial strain.

During the following days, WBC, C-reactive protein and the temperature returned to normal range and the patient general conditions markedly improved. A new echocardiographic examination was performed on day 6 with findings similar to those previously observed. On day 8 , the patient underwent dobutamine stress echocardiography, which was negative for ischemia; and coronary angiography, which showed only a mild reduction in the medial portion of the left anterior descending coronary artery, likely due to myocardial bridging, and a small plaque close to the crux, with no critical stenosis.

The patient was discharged on day 9 without symptoms and in good condition, on antibiotic therapy for 4 days and low-dose metoprolol $(25 \mathrm{mg}$ twice daily).

\section{Discussion}

Our patient presented to the hospital emergency room with symptoms of urinary tract infection. He had no chest pain or other cardiac symptoms at the time of hospitalization. The ECG, however, showed significant alterations not correlated to the echocardiographic wall motion abnormalities. No ischemia was detected at stress echocardiography, and coronary angiography revealed no critical stenosis. Although it is well known that myocardial bridging may cause ischemia and predispose to coronary artery spasm [1,2], it is extremely unlikely that this occurs without any typical symptoms. In addition, wall motion abnormalities were located in the inferior and infero-lateral regions without affecting the interventricular coronary artery, the predominant site of myocardial bridging-induced ischemia.

E. coli infection has been shown to stimulate the production of IgM $\lambda$ with subsequent human antimouse antibody interference in cTnI measurement, showing persistently high values of this cardiac enzyme for several days [3]. The case described in the literature is quite different from ours in that our patient showed signs of myocardial injury (ST-T changes on the ECG and wall motion abnormalities at echocardiography). Moreover, peak cTnI levels were moderately high, and cTnI elevation lasted only a few hours. As a consequence, these asymptomatic alterations in cardiac function were interpreted as indicating myocardial injury due to E. coli sepsis.

Many authors have investigated the clinical significance of myocardial injury in patients with bacteremia, suggesting that elevated cTnI concentrations may be a sign of toxic and inflammatory reaction, a risk factor for more severe infectious disease and a surrogate marker for death $[4,5]$, although no general agreement exists on this issue [6].

The way by which $E$. coli sepsis leads to myocardial injury remains to be clearly elucidated [7, 8]. In viral myocarditis, myocardial injury seems to develop in three phases: during the first phase direct destruction of cardiomyocytes occurs by virusmediated lyses; the second phase develops as a result of an autoimmune-mediated response induced by epitopes shared between the viral and cardiac antigens. Finally, in the third phase, myocardial

Figure 2. ECG performed one hour later, on the intensive cardiac care unit admission. 
remodeling leading to dilated cardiomyopathy develops as a result of extensive myocardial injury [9].

In the literature $E$. coli is not mentioned among the bacteria that may cause myocarditis [9]. Nonetheless, all experimental models of cardiac dysfunction during sepsis or septic shock use $E$. coli-derived lipopolysaccharide endotoxin (LPS) [10-14]. On this basis, we hypothesize that E. coli infection exerts toxic effects resulting from the liberation of LPS. In turn, LPS may lead to an increase in the blood concentration of several cytokines, such as tumor necrosis factor- $\alpha$ and interleukin- 1 [11], whose are known to induce depression of cardiac contractility [15]. In fact, it has been suggested that tumor necrosis factor- $\alpha$ enhances the permeability of myocytes membrane with leakage of cTnI from the cytosolic pool. This phenomenon may initially induce myocardial reversible dysfunction, similar to myocardial hibernation $[8,16]$, while the myocyte-contraction complex remains intact [11]. In this regard, some authors observed no contraction band necrosis in septic hearts, a sign of irreversible myocardial injury [17], and reported that cTnI I release is often extremely rapid with steep rising and decline within a few hours. These findings are not consistent with structural damage, which is characterized by a slow release of cTnI lasting several days $[11,18]$.

In the present case, normalization of both ECG (Fig. 3) and cTnI concentrations (Fig. 4) within a few hours, together with normal creatine-kinase levels showing a release curve in plasma similar to that of cTnI [19, 20], are suggestive of myocardial injury and seem to support this hypothesis.

In addition, it is worth noting that $\mathrm{cTnI}$ and $\mathrm{WBC}$ curves perfectly matched (Fig. 4), and C-reactive protein also normalized in a few days due to a direct relationship between cTnI release and immunological response to sepsis.

Available evidence, however, is not entirely consistent with the hypothesis of reversible damage. By reviewing histopathological slides of septic shock hearts, Beranek [21] suggested a contributing role of cardiomyocyte apoptosis, a process that may be only partially reversible. Conversely, Yin et al. [12] showed that LPS infusion causes myocardial lysosome damage and an increase in the expression of inducible nitric oxide synthase as well as of some adhesion molecules such as $\mathrm{P}$ - selectin and L-selectin, with subsequent thrombus formation. By identifying thrombus formation as the cause of cardiac dysfunction, John et al. [22] demonstrated that treatment with recombinant human activated protein $\mathrm{C}$, which has potent anticoagulant effects, results in outcome improvement.

Other authors have focused their attention on functional alterations. Impairment in myofilament $\mathrm{Ca}^{2+}$ sensitivity has been described in the septic heart [23], which may account for contractile dysfunction. Fenofibrate pretreatment has been shown to be effective in preventing this condition by stimulating peroxisome proliferator-activated receptor- $\alpha$, which modulates cytokine production [13]. Conversely, intravenous infusion of the $\mathrm{Ca}^{2+}$ sensitizer levosimendan has been proven to be ineffective [14].

In conclusion, we described a case of asymptomatic myocardial injury with ECG, echocardiographic and $\mathrm{cTnI}$ alterations in E. coli sepsis induced by post-prostatectomy urinary tract infection. It is likely that the mechanisms underlying myocardial injury in the septic heart are complex and multifaceted, ranging from functional to structural alterations that all combine to cause cardiac dysfunction. Some of them have already been identified and thoroughly investigated; many others remain to be discovered. Further studies are needed to better under-

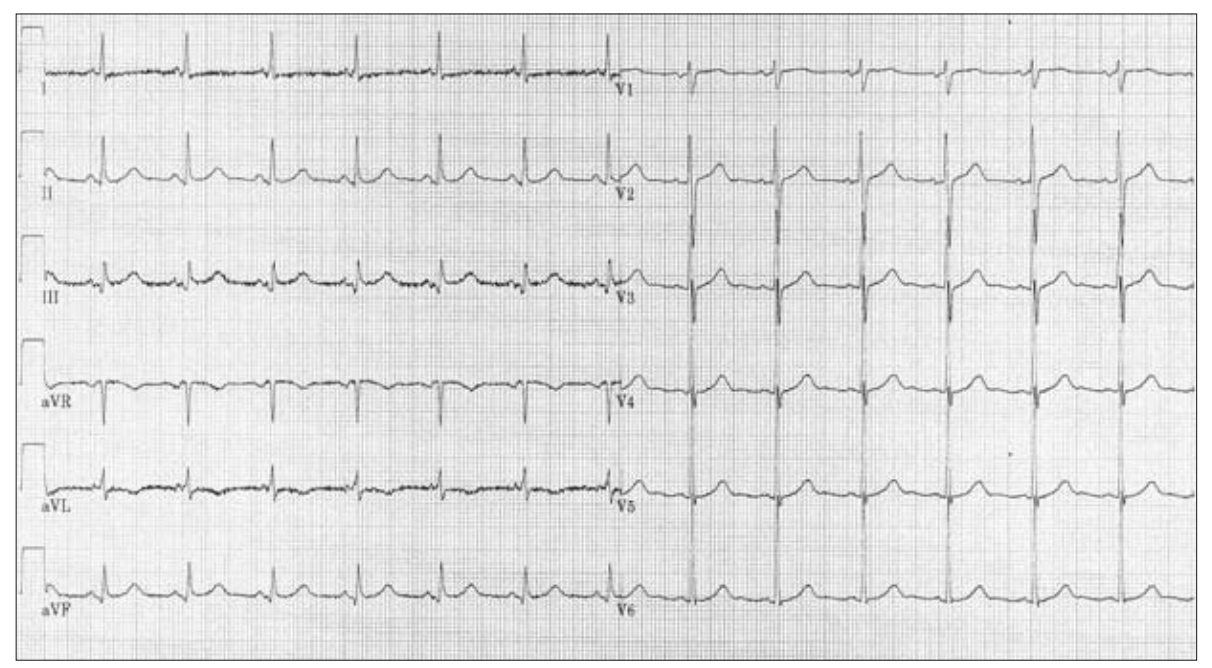

Figure 3. ECG performed 10 hours after the intensive cardiac care unit admission.

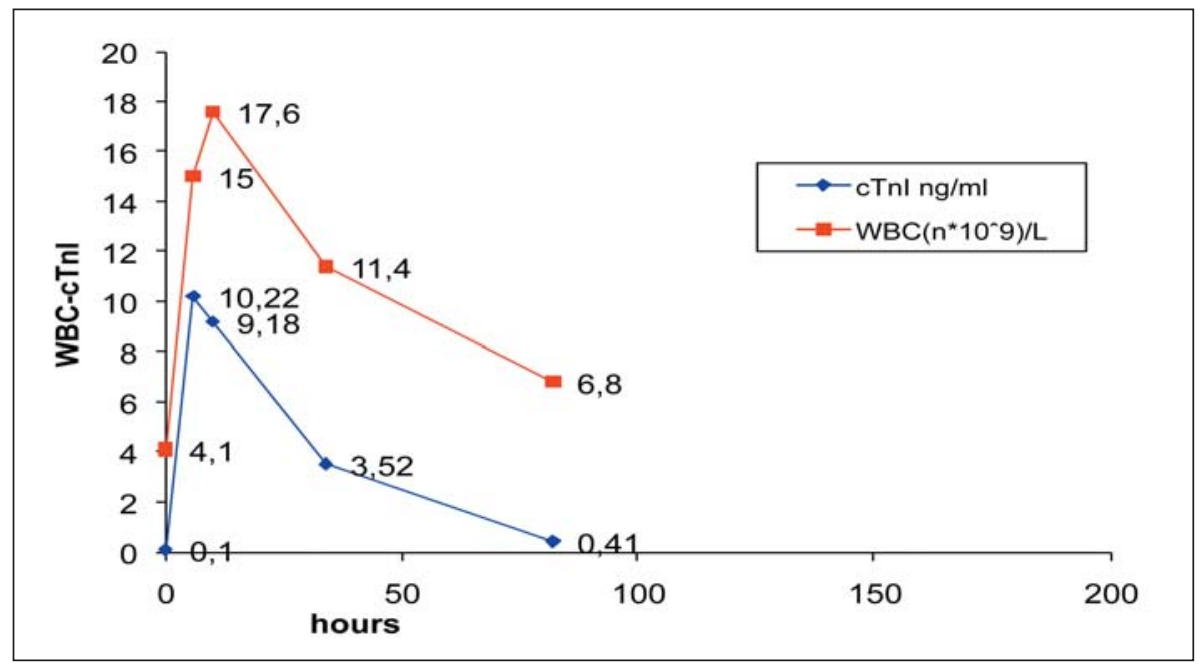

Figure 4. Cardiac troponin I (cTnI) and white blood cell count (WBC) curves. Of note, the matching of the two curves. 
stand the pathophysiology of septic heart, and to find appropriate management strategies for the treatment and prevention of such condition.

\section{Riassunto}

I segni e sintomi tipici dell'infarto miocardico acuto sono ben noti. Le alterazioni dell'ECG, dell'ecocardiogramma e dei markers di necrosi miocardica sono utili nel confermare la diagnosi. Tuttavia alcuni di questi elementi compaiono anche nella miocardite che rappresenta una potenziale diagnosi differenziale.

In questo articolo si descrive un caso di sepsi indotta da Escherichia Coli che ha causato un inusuale danno miocardico (miocardite) con alterazioni ECG che mimavano un infarto miocardico acuto. Si è inoltre valutato il possibile meccanismo fisiopatologico alla base di questa lesione considerando le ultime evidenze scientifiche provenienti anche dalla ricerca di base.

\section{References}

1. Xiang DC, Gong ZH, He JX, Ruan YJ, Xie ZH. Characteristics of stress tests and symptoms in patients with myocardial bridge and coronary artery spasm. Coron Artery Dis 2009; 20: 27-31.

2. Zurick AO 3rd, Klein JL, Stouffer GA. Scintigraphic evidence of severe myocardial hypoperfusion in a patient with left anterior descending coronary artery bridging. Case report and review of the literature. Am J Med Sci 2008; 336: 498-502.

3. Covinsky M, Laterza O, Pfeifer JD, Farkas-Szallasi T, Scott MG. An IgM $\lambda$ antibody to Escherichia coli produces false-positive results in multiple immunometric assays. Clin Chem 2000; 46(8 Pt 1): 1157-1161.

4. Kalla C, Raveh D, Algur N, Rudensky B, Yinnon AM, Balkin J. Incidence and significance of a positive troponin test in bacteremic patients without acute coronary syndrome. Am J Med 2008; 121: 909-915.

5. Ammann P, Fehr T, Minder EI, Günter C, Bertel O. Elevation of troponin I in sepsis and septic shock. Intensive Care Med 2001; 27: 965-969.

6. Oliveira NS, Silva VR, Castelo JS, Elias-Neto J, Pereira FE, Carvalho WB. Serum level of cardiac troponin I in pediatric patients with sepsis or septic shock. Pediatr Crit Care Med 2008; 9: 414-417.

7. $\mathrm{Wu} \mathrm{AH}$. Increased troponin in patients with sepsis and septic shock: myocardial necrosis or reversible myocardial depression? Intensive Care Med 2001; 27: 959-961.

8. Fernandes CJ. Sepsis-induced myocardial depression: where is the missing link? Crit Care Med 2007; 35: 972-973.
9. Dennnert R, Crijns HJ, Heymans S. Acute viral myocarditis. Eur Heart J 2008; 29: 2073-2082.

10. Peek SF, Apple FS, Murakami MA, Crump PM, Semrad SD. Cardiac isoenzymes in healthy Holstein calves and calves with experimentally induced endotoxemia. Can J Vet Res 2008; 72: 356-361.

11. van Bockel EA, Tulleken JE, Muller Kobold AC, et al. Cardiac troponin I release and cytokine response during experimental human endotoxaemia. Intensive Care Med 2003; 29: 1598-1600.

12. Yin GQ, Du KH, Gu FR, et al. Early-phase endotoxic shock-induced myocardial injury increases iNOS and selectin expression in macaque primate. Heart Lung Circ 2007; 16: 85-92.

13. Jozefowicz E, Brisson H, Rozenberg S, et al. Activation of peroxisome proliferators-activated receptor- $\alpha$ by fenofibrate prevents myocardial dysfunction during endotoxemia in rats. Crit Care Med 2007; 35: 856-863.

14. Cunha-Goncalves D, Perez-de-Sa V, Dahm P, Cardiovascular effects of levosimendan in the early stages of endotoxemia. Shock 2007; 28: 71-77.

15. Kumar A, Thota V, Dee L, Olson J, Uretz E, Parrillo JE. Tumor necrosis factor $\alpha$ and interleukin $1 \beta$ are responsible for in vitro myocardial cell depression induced by human septic shock serum. J Exp Med 1996; 183: 949-958.

16. Levy RJ, Piel DA, Acton PD, et al. Evidence of myocardial hibernation in the septic heart. Crit Care Med 2005; 33: 2752-2756

17. ver Elst KM, Spapen HD, Nguyen DN, Garbar C, Huyghens LP, Gorus FK. Cardiac troponins I and T are biological markers of left ventricular dysfunction in septic shock. Clin Chem 2000; 46: 650-657.

18. Katus HA, Remppis A, Scheffold T, Diederich KW, Kübler W. Intracellular compartmentation of cardiac troponin $\mathrm{T}$ and its release kinetics in patients with reperfused and nonreperfused myocardial infarction. Am J Cardiol 1991; 67: 1360-1367.

19. Katus HA, Diederich KW, Schwarz F, Uellner M, Scheffold T, Kübler W. Influence of reperfusion on serum concentrations of cytosolic creatine kinase and structural myosin light chains in acute myocardial infarction. Am J Cardiol 1987; 60: 440-445.

20. Lee TH, Goldman L. Serum enzyme assays in the diagnosis of acute myocardial infarction. Recommendations based on a quantitative analysis. Ann Intern Med 1986; 105: 221-233.

21. Beranek JT. Cardiomyocyte apoptosis contributes to the pathology of the septic shock heart. Intensive Care Med 2002; 28: 218.

22. John J, Awab A, Norman D, Dernaika T, Kinasewitz GT. Activated protein $\mathrm{C}$ improves survival in severe sepsis patients with elevated troponin. Intensive Care Med 2007; 33: 2122-2128.

23. Yasuda S, Lew WY. Lipopolysaccharide depresses cardiac contractility and $\beta$-adrenergic contractile response by decreasing myofilament response to $\mathrm{Ca}^{2+}$ in cardiac myocytes. Circ Res 1997; 81: 1011-1020. 